\title{
Letter to the Editors concerning the paper "Ambient air pollution and lung cancer in Poland: research findings and gaps"
}

\author{
Michał Krzyżanowski ${ }^{1}$, Wojciech Hanke² \\ 'King's College London, UK \\ ${ }^{2}$ Nofer Institute of Occupational Medicine in Łódź, Poland
}

ADDRESS FOR CORRESPONDENCE: Michał Krzyżanowski, King's College London, 150 Stamford Str., SE1 9NH London, UK, e-mail: michal.krzyzanowski@kcl.ac.uk

In his recent paper on "Ambient air pollution and lung cancer in Poland: research findings and gaps", Mark Parascandola evaluates available evidence on the etiology of lung cancer as related to air pollution exposure in Poland [1].

The author makes an important remark that estimating the cancer burden of air pollution in a given country requires country-specific data, including information on effects of the exposure on cancer. He correctly says that current estimates of both the relative and attributable risk "are based on relatively limited data, applying risk estimates from studies in other countries to mortality rates in Poland", which requires numerous assumptions in the case of estimating cancer risk. He then states that "(...) the necessary data sources and studies to estimate the size of this (exposure) burden are lacking in Poland".

Mark Parascandola identifies several gaps, which should be overcome in order to provide more in-depth assessment of the burden of air pollution on lung cancer in Poland. Two of them are crucial, namely the lack of epidemiological studies and the deficiencies due to limited availability of historical data on ambient air pollution. There is no doubt that the results of prospective cohort studies are generally much more valid when the relationship between air pollution exposure and cancer outcomes is investigated. Poland has never undertaken such a project. The data deriving from ecological and case-control studies, as reviewed by Mark Parascandola, are inconsistent and have substantial limitations due to the challenge of estimating historical exposure to air pollution and weakness of the study design.

However, we strongly disagree that, in view of the lacking local studies, the available global evidence is insufficient to estimate the burden of air pollution exposure to cancer risk in Poland or in any other country, with no local epidemiological study completed (i.e., most of the world). Such global evidence is constantly growing owing to the large cohort studies conducted in the United States, Canada, Europe, China, and South East Asia. Only after the Huang et al. [2] meta-analysis was conducted, several papers were published supporting and strengthening earlier conclusions and risk estimates. Some are based on millions of people followed for a decade or more $[3,4]$. They include a prospective cohort study of around 190 thousand adults followed for 16 years in China [5]. Notably, an analysis of AHSMOG-2 cohort of approximately 80 thousand adults in USA, out of which $81 \%$ were never smokers, confirms strong effect of the exposure to air pollution also in never smokers [6]. The exposure ranges from PM2.5 levels far below up to far exceeding those observed in Poland.

All countries can and should profit from this combined evidence to estimate the magnitude of the impacts of air pollution exposure on lung cancer and on other, more numerous diseases associated with the exposure. Using this evidence, the WHO provides such estimates for each country in the world, including Poland, with approximately 3 thousand cancer deaths and over 29 thousand deaths from all causes, attributed to air pollution in 2016 [7]. Such estimates, combined with underlying global evidence on causality of the associations, are sufficient and alarming arguments for policies and actions aiming at reduction of the exposure and its health effects. Indeed, Mark Parascandola notes that "explosion in public awareness and concern over air pollution in Poland over the past year has given a sense of urgency to the 
problem". Several actions have already been undertaken, e.g., enactments regulating minimum standards for boilers, support from local governments for replacement of old heating installations, anti-smog legislation, and the ongoing legislation proposals regarding the quality of coal used for house heating. These are all important steps forward. However, a lot remains still to be done, and both global and local evidence on the impacts of air pollution on health will remain the driving argument for the actions.

Epidemiological cohort studies would be necessary both to document the changes in population exposure resulting from the implemented policies and to demonstrate their effectiveness in preventing health effects. Studies on lung cancer might be the most difficult part of this research, owing to long latency time of the disease and its smaller frequency as compared to cardiovascular diseases also causally connected to air pollution. However, retrospective exposure assessment and modelling as well as the use of data from existing cancer registration might enable national case-control studies to contribute to the national and global evidence base. Further improvement of the data from routine monitoring of air pollution, conducted by agencies of the State Environment Inspectorate as well as development of high-resolution air quality modelling, will be necessary elements of this research.

The present situation is very similar to the one in 1990s, when large anti-smoking campaigns were launched in Poland. Millions of Poles quit smoking [8]. The incidence and mortality rates from lung cancer started to gradually decline and we were able to notice a positive trend [9]. This finding has speeded up the actions of the national Quit Smoking movements even more. As they say, you go faster when you know you are on the right track.

\section{DISCLOSURE}

The authors report no conflict of interest.

\section{References}

1. Parascandola M. Ambient air pollution and lung cancer in Poland: research findings and gaps. J Health Inequal 2018; 4: 3-8.

2. Huang F, Pan B, Wu J, et al. Relationship between exposure to PM2.5 and lung cancer incidence and mortality: a meta-analysis. Oncotarget 2017; 8: 43322-43331

3. Pinault LL, Weichenthal S, Crouse DL, et al. Associations between fine particulate matter and mortality in the 2001 Canadian Census Health and Environment Cohort. Environ Res 2017; 159: 406-415.

4. Pun VC, Kazemiparkouhi F, Manjourides J, Suh HH. Long-term PM2.5 exposure and respiratory, cancer, and cardiovascular mortality in older US adults. Am J Epidemiol 2017; 186: 961-969.

5. Yin P, Brauer M, Cohen A, et al. Long-term particulate matter exposure and nonaccidental and cause-specific mortality in a large national cohort of Chinese men. Environ Health Perspect 2017; 125: 117002.
6. Gharibvand L, Shavlik D, Ghamsary M, et al. The association between ambient fine particulate air pollution and lung cancer incidence: results from the AHSMOG-2 study. Environ Health Perspect 2017; 125: 378-384.

7. WHO World Health Organization 2018. Global Health Observatory data repository. Available from: http://apps.who.int/ gho/data/node.main.BODAMBIENTAIRDTHS?lang=en (accessed: 10 August 2018).

8. Zatoński WA, Zatoński M, Janik-Koncewicz K, et al. Hundred years of cigarette smoking in Poland: three phases of the tobacco epidemic. J Health Inequal 2017; 3: 118-122.

9. Zatoński WA, Tukiendorf A, Zatoński M, et al. Lung cancer mortality decline among middle-aged men and women in Poland and the UK. J Health Inequal 2017; 3: 123-126.

\section{AUTHORS' CONTRIBUTIONS}

MK, WH prepared the research concept, wrote the article and approved the final version of the publication. 